\title{
THE TOXIC FACTORS IN EXPERIMENTAL TRAUMATIC SHOCK. I. PHYSIOLOGIC EFFECTS OF MUSCLE LIGATION IN THE DOG ${ }^{1}$
}

\author{
By I. T. NATHANSON, A. L. NUTT, A. POPE, P. C. ZAMECNIK, J. C. AUB, \\ A. M. BRUES, AND S. S. KETY \\ (From the Medical Laboratories of the Collis P. Huntington Memorial Hospital of \\ Harvard University at the Massachusetts General Hospital. Boston, Massachusetts)
}

(Received for publication April 9, 1945)

The experimental study of traumatic shock requires the use of a reproducible procedure for damaging muscles and surrounding tissues. Since the classical method of Cannon and Bayliss (1), many techniques have been employed ( 2 to 5 ). By the use of such methods, a relatively uniform clinical result can be obtained in a series of experiments, but the exact amount of tissue injured and of accumulated fluid cannot be measured accurately. Collection of the traumatic exudate is likewise a difficult procedure although its composition has been the subject of investigation (6).

In the course of making a study of electrolyte and water shifts in shock, it became desirable to utilize a method whereby a known or measurable amount of tissue could be damaged by temporary interruption of its blood supply. The method described in this paper was evolved in order to accomplish this.

This method also has certain other important advantages which have made it very useful in the study of the etiology and therapeusis of traumatic shock. It is traumatically less severe than many methods, and therefore does not usually produce overwhelming shock. This provides the opportunity of differentiating possible early and primary changes in physiological responses which might be obscured with more vigorous techniques. Moreover, it is suitable for the study of the effects of therapeutic procedures to which an excessively traumatized animal could not be expected to respond.

As a result of the procedure, fluid accumulates locally in the region of the injured muscles. Since

1 This is reprint No. 605 of the Cancer Commission of Harvard University.

The work described in this paper was done under a contract, recommended by the Committee on Medical Research, between the Office of Scientific Research and Development and the Massachusetts General Hospital. this accumulation is largely limited to the lower part of the legs, it is possible to estimate it as a function of time by measuring volume changes in the limbs up to the groin. The procedure has also been modified so that the accumulating fluid can be collected completely; in this way, factors affecting the rate of extravasation in a traumatized area can be evaluated, and the fluid itself can be obtained in large quantities for investigation of its chemical composition, its physiologic properties, and its bacterial flora.

\section{TECH NIQUE OF OPERATION}

Aseptic precautions are used throughout. All animals were anaesthetized by means of sodium pentobarbital, 30 mgm. per $\mathrm{kgm}$. given intravenously. The hair of both hind limbs of the dog is carefully clipped and shaved from the paw to the inguinal fold. The shaved skin is then scrubbed thoroughly with soap and water, dried with ether, and painted with tincture of iodine. The hips are then acutely flexed, the legs brought into extension and anchored to the table. The legs are draped with sterile towels and a small laparotomy sheet. A linear incision is made in the middle of the skin of the calf extending from the level of the attachment of the tendo Achillis to a point just proximal to the popliteal space. The skin edges are protected by sterile towels or gauze sponges which are secured by a continuous silk suture. The fascia overlying the calf muscles is then incised over the entire length of the wound, and retracted laterally. By blunt dissection with the finger, the triceps surae muscles (gastrocnemius and soleus) are isolated together from the plantaris muscle, the posterior tibial and peroneal nerves, and the muscles immediately posterior to the tibia and fibula. This frees the triceps surae muscles except at their origins and insertions. The vessels and nerves in the popliteal space are partially dissected free from the surrounding fat. Occasionally, it is necessary to divide the peroneal or posterior tibial nerve to secure adequate isolation of the muscles. Several small vessels entering the lateral portion of the triceps surae may have to be secured and ligated. A rubber band approximately $10 \mathrm{~cm}$. long and $0.7 \mathrm{~cm}$. wide is looped around the muscles and passed over them to a point as close as possible to their origin. This is facilitated by passing a cloth tape through the long loop. 
When the desired position for the rubber tourniquet is obtained, the loop is closed as tightly as possible and secured by a tape tie which was previously placed (see diagram, Figure 1). The tendo Achillis is ligated so as to occlude the blood flow at that end. The incision is closed.

At the end of 5 hours, the wound is prepared, draped, and opened at its proximal end. The tourniquet is divided and removed. The arteries distal to the site of the tourniquet are palpated, and the veins are emptied by mild manual pressure and allowed to refill in order to estimate the integrity of the circulation. Other methods to estimate this are described later. The wound is then resutured and the limbs returned to the extended position.

When complete isolation of the triceps surae from the surrounding tissues is desired, the technique is modified at the time of the first procedure as follows. The tendo Achillis is divided close to its insertion and the cut ends ligated. A rolled rubber sheath is then unrolled over the muscles as far as the tourniquet. The proximal (open) end is anchored in position by a small rubber band. The skin and fascia are then closed in one layer by a continuous silk suture and the limbs are brought into extension. Five hours later the tourniquet is removed as described
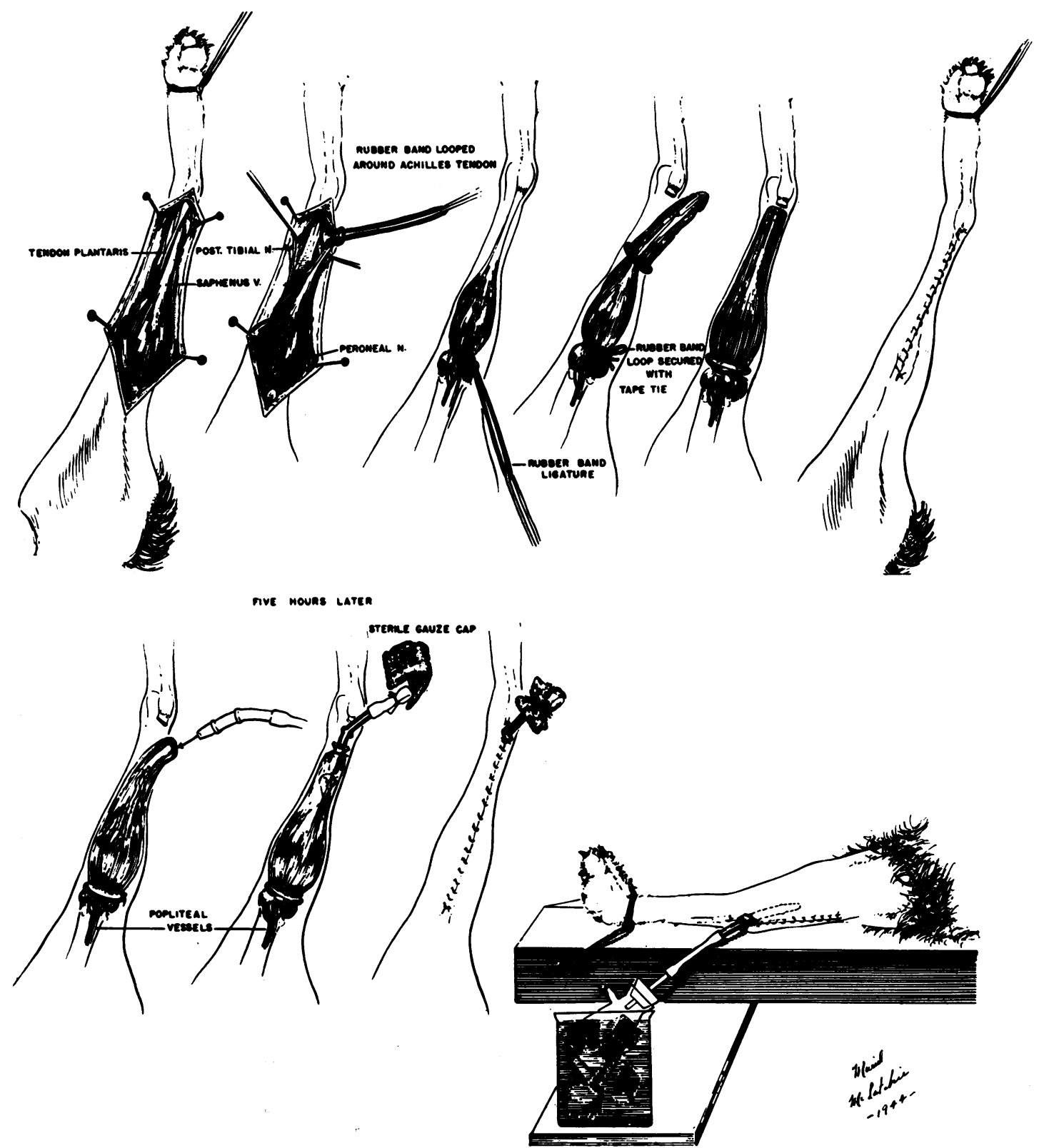

Fig. 1. Diagrams Illustrating Technique of Muscle Ligation (For explanation see text) 


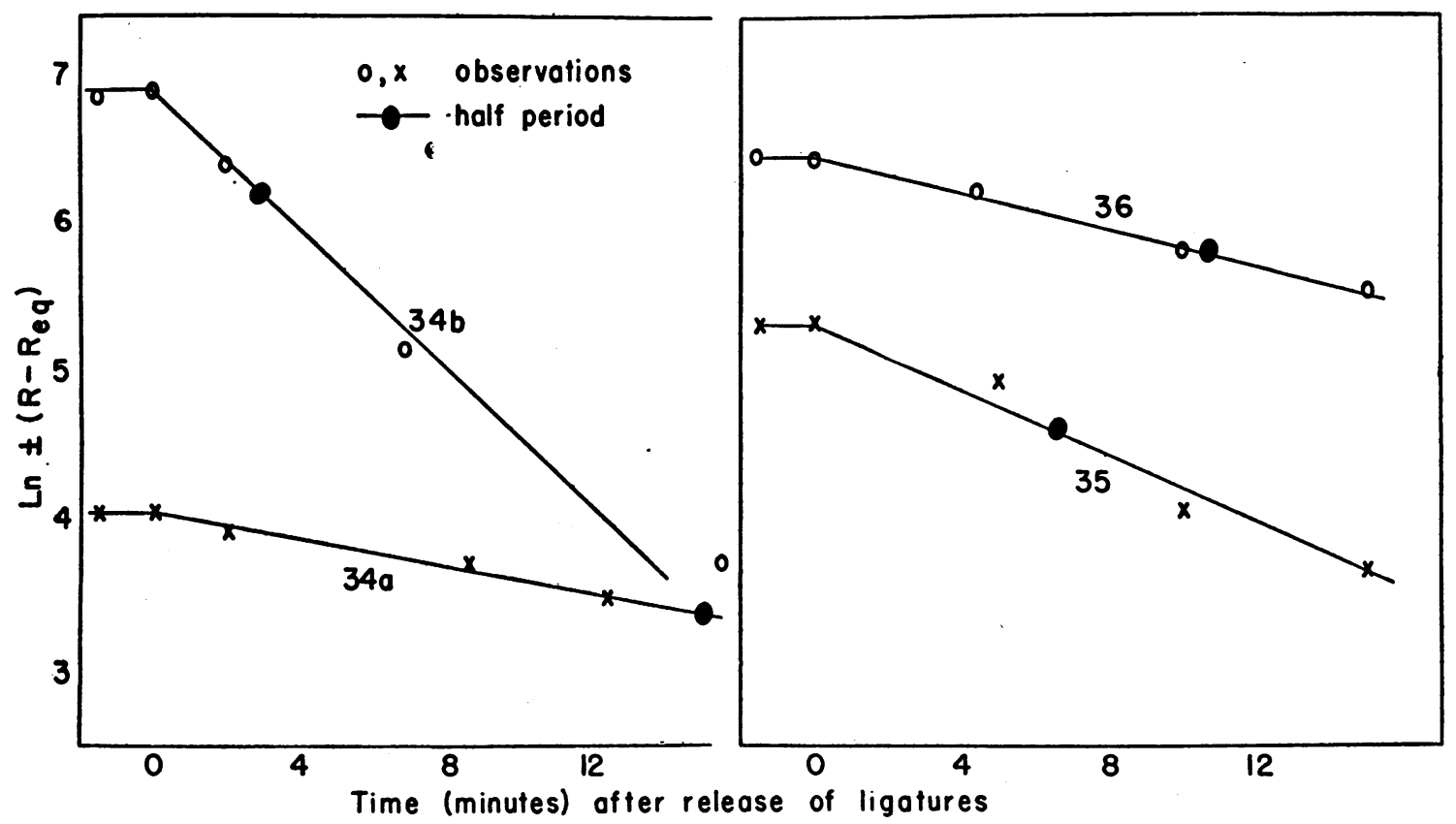

Fig. 2. Graph of Changes in Measured Radioactivity Following Release of Ligatures, after Injecting $\mathrm{NA}^{24}$ into Ligated MUScles

The natural logarithm of the (positive) difference between each reading and the equilibrium reading * has been plotted against time. The half-period in each case is indicated on the curve. Note that each set of observations, plotted in this way, approximates a straight line, indicating that equilibrium is approached through a simple exponential curve. As noted in the text, the curves thus calculated always slope downwards whether loss or uptake of the isotope is measured.

34a. Readings taken in left axilla after release of right muscle group (containing $\mathrm{Na}^{24}$ ).

34b. Readings from area of left muscle group following its subsequent release.

35. Readings taken over right muscle group (containing $\mathrm{Na}^{24}$ ) following its release.

36. Readings from left axilla, as in 34a.

* All readings corrected for background and for decay of the isotope.

above and the wound closed. If fluid collection from the tourniqueted muscle is desired, the following procedure is utilized.

Fluid collection. The wound is reopened throughout its entire length and the rubber tourniquet is divided and removed. The open end of the sheath is then carried as close as possible to the muscle origins. The closed distal tips of the sheath is incised and the end of a curved glass tube about $1 \mathrm{~cm}$. in diameter is inserted. This is secured by several ligatures placed about the sheath above and below a collar on the tube. At the distal end of the tube is placed a length of rubber tubing, which had been previously folded on itself, secured by a ligature, and covered by a sterile gauze sponge (see Figure 1 ). The tube is then led out of the distal end of the incision or through a stab wound on the lateral skin flap. The skin and fascia are closed in one layer with a continuous silk suture and the glass tube is anchored to the skin by a purse-string suture which is tied proximal to a collar on the tube. The legs are brought into extension and secured. The gauze cap is removed from the rubber tubing and the tubing unfolded. The distal end of the tubing is then placed over a sterile glass tube which had been inserted in a rubber stopper attached to a sterile suction flask. Sterile cotton is inserted into the open end of the side arm of the flask. The flask is then immersed in a beaker of ice and water which is placed on a shelf attached to the operating table. Thus the fluid which exudes from the muscle is collected in the flask. Fluid comes out rapidly, usually after a short lag period, and after some hours the flow subsides. The collection is continued for about 5 hours or until the muscles cease to yield fluid.

Reestablishment of circulation following anoxia. In addition to observations on arterial pulsation in muscles following release of ligatures, radioactive tracers were employed in some cases to determine reestablishment of circulation. Just before the ligatures were released, 1 or $2 \mathrm{ml}$. of isotonic sodium chloride containing a suitable amount of radioactive sodium $\left(\mathrm{Na}^{24}\right)$ were injected into the substance of one of the tied muscles. Equilibration of the labelled sodium chloride with that outside the muscle was followed by means of readings taken on a GeigerMuller counter held in position over the injected muscle, the uninjected muscle, or the left axilla. Following re- 
lease of tourniquet, there was a prompt decrease in radioactivity over the injected area and increase over other areas in all cases. Final readings were taken after equilibrium had apparently been reached.

On the supposition that redistribution of the isotope inside and outside the muscle might reach equilibrium through a simple exponential curve, the logarithms of the differences between each reading and the final equilibrium reading were plotted as ordinates against the time after release of ligatures. It will be noted that by plotting the logarithm of each difference as a positive value, all curves will show a downward slope whether one is measuring loss of isotope from the injected area or its increase in other areas $\left(y=K\left(1-\Sigma^{-k t}\right)\right.$ or $y=K^{-k t}$, respectively). The resulting graphs showed approximately straight lines in all cases (Figure 2), and from these slopes half-periods have been calculated (i.e., time required for the exchange to become half completed). A tabulation of the findings follows:

Dog 34. Muscles were isolated by sheaths (not drained). $\mathrm{Na}^{26}$ was injected into the right gastrocnemius muscle. Readings taken over the left axilla (a) showed increase of radioactivity with half-period 15 minutes, following release of right muscle group. Thirty minutes later, the left muscle group was released while readings were made over this area (b), indicating penetration of $\mathrm{Na}^{24}$ into the uninjected muscle. Half-period $3 \frac{1}{2}$ minutes.

Dog. 35. No sheaths used in this experiment. $\mathrm{Na}^{26}$ injected into right gastrocnemius muscle; axillary readings made while ligature was released. Half-period 10\%/2 minutes.

Dog. 36. Muscles were isolated by sheaths (not drained). $\mathrm{Na}^{24}$ injected into right gastrocnemius muscle; axillary readings made while ligature was released. Halfperiod $10 \frac{1}{2}$ minutes.

In 2 additional experiments the state of the muscle circulation was tested before and after release of ligatures by a semi-quantitative procedure. Immediately following application of ligatures, $1 \mathrm{ml}$. of 1 per cent phenol red (10 mgm.) was injected into the substance of each muscle group. Urinary excretion of the dye was then followed and calculated as percentage of the injected amount. The results follow:

Dog 47. Muscles were sheathed and drained. Excretion of the dye in the first hour after application of ligatures was 3.8 per cent. Excretion in following 4 hours, 1.5 per cent. In 35 minutes after first release 4.6 per cent was excreted; second ligature was then released and 5.9 per cent was excreted in the ensuing 40 minutes. Total excretion in 14 hours, 34.4 per cent.

Dog 48. Sheaths were not used. During 5-hour period of application of ligatures, 0.4 per cent of the dye was excreted. In 30 minutes after first release, 5.7 per cent; in 1 hour after second release, 11.2 per cent. Total in 10 hours, 33.9 per cent.

In the first case there was escape of dye soon after injection, which did not occur in the second case. In both cases a prompt excretion occurred following release of each tie, confirming the results with $\mathrm{Na}^{24}$.

The above results show that the procedure usually causes a nearly complete cessation of circulation in the muscles, and that prompt reestablishment of the circulation after release of ligatures is the rule.

Mass of muscle involved. In a few cases the triceps surae groups were weighed either before or after release of ligatures. Three specimens taken while ties were in

TABLE I

Results of muscle tying procedure

(Average values for blood pressure, venous oxygen content and blood hemoglobin at various stages in the procedure)

\begin{tabular}{|c|c|c|c|c|c|c|}
\hline & $\begin{array}{c}\text { Number } \\
\text { of } \\
\text { dogs }\end{array}$ & Initial & $\begin{array}{l}\text { Before } \\
\text { release } \\
\text { of ties }\end{array}$ & $\begin{array}{l}30 \text { minutes } \\
\text { after release } \\
\text { of ties }\end{array}$ & $\begin{array}{l}6 \text { hours } \\
\text { after release } \\
\text { of ties }\end{array}$ & (Final) range \\
\hline $\begin{array}{l}\text { Without drainage-no shock } \\
\text { Blood pressure } \\
\text { mm. } \mathrm{Hg} \\
\text { Venous } \mathrm{O}_{2} \\
\text { volumes per cent } \\
\text { Hemoglobin } \\
\text { grams per cent } \\
\text { Without drainage-shock* } \\
\text { Blood pressure } \\
\text { mm. Hg } \\
\text { With drainage-no shock } \\
\text { Blood pressure } \\
\text { mm. Hg } \\
\text { Venous } \mathrm{O}_{2} \\
\text { volumes per cent } \\
\text { Hemoglobin } \\
\text { grams per cent }\end{array}$ & $\begin{array}{r}35 \\
8 \\
7\end{array}$ & $\begin{array}{r}113 \\
14.3 \\
12.8 \\
133 \\
128 \\
13.3 \\
13.0\end{array}$ & $\begin{array}{r}130 \\
14.1 \\
16.6 \\
141 \\
146 \\
14.3 \\
13.5\end{array}$ & $\begin{array}{c}124 \\
12.5 \\
16.6 \\
125 \\
134 \\
11.2 \\
13.8\end{array}$ & $\begin{array}{c}100 \\
9.1 \\
17.8 \\
59 \\
118 \\
12.2 \\
16.3\end{array}$ & $\begin{array}{c}90 \text { to } 110 \\
8.4 \text { to } 9.8 \\
16.0 \text { to } 19.6 \\
46 \text { to } 68 \\
80 \text { to } 140 \\
6.0 \text { to } 16.7 \\
14.8 \text { to } 20.8\end{array}$ \\
\hline
\end{tabular}

Note: The 10 dogs submitted to simple muscle tying without drainage have been divided into 2 groups depending upon whether shock occurred (defined arbitrarily as blood pressure below $70 \mathrm{~mm}$. $\mathrm{Hg}$ ). No dogs in the group treated with drainage showed signs of shock.

* No values available for venous oxygen and hemoglobin. 
place had a mean weight equivalent to $0.35 \pm 0.08$ per cent of body weight; 7 specimens taken 6 hours after release weighed $0.52 \pm 0.08$ per cent of body weight. Thus, the total mass of tissue involved in the bilateral procedure includes roughly 1 per cent of body weight.

\section{RESULTS}

Uncomplicated muscle ligation. Ten dogs were subjected to the procedure without drainage of fluid, the muscles being tied bilaterally for a $51 / 2^{-}$ hour period. Six hours after release of the ligatures, 3 of the 10 dogs had blood pressures below 70 and were considered to be in shock. Two of these died within the next hour and the third was sacrificed. The remaining 7 had blood pressures ranging between 90 and 110, and were considered not to be in shock. Two of these were sacrificed within 7 hours and the remainder were allowed to survive from 20 to 38 hours. In Table I, we have summarized observations on these dogs which have been divided into 2 groups depending upon whether or not shock occurred. In 2 dogs without shock, observations were made on venous oxygen content and on hemoglobin. A moderate hemoconcentration was observed, and the venous oxygen levels declined somewhat suggesting a decrease in cardiac output.

Procedure with drainage. All 35 animals in this group failed to show evidence of shock within 6 hours after release of ligatures. Table I shows that there was little change in the venous oxygen content, but hemoconcentration regularly occurred after release.

In addition to the experiments tabulated here, a number of dogs were subjected to considerable bleeding (over 0.5 per cent of the body weight equivalent in blood), and these will be discussed elsewhere. Seven dogs done without sterile precautions, of which 5 received $500 \mathrm{mgm}$. sodium thiocyanate intravenously, and all of which were bled an amount exceeding 1 per cent of body weight, have been omitted from the present series. Although all of these dogs developed shock within 5 hours after release, it is clear that the procedure was complicated by other factors potentially detrimental to the circulation.

Accumulation of fluid. Local swelling was almost invariably observed following release of ties. It will be seen (Table I) that hemoconcentration occurred in those animals where drainage was not employed, as well as in those whose extrava- sated fluid was drained. Unfortunately, there are no data to show the degree of hemoconcentration in the 3 which developed shock.

In an attempt to improve the yield of fluid from drained muscles, slow infusions of physiologic salt solution were given intravenously over a 2 to 3 hour period beginning before release of the ligatures. The amount of fluid given was approximately equal to the animal's theoretical plasma volume. Such experiments are compared with controls in Table II. It is seen that there is wide variation in fluid output in both groups of animals

TABLE II

Effect of intravenous saline infusion on production of fluid following muscle ligation

\begin{tabular}{l|c|c|c}
\hline \hline & $\begin{array}{c}\text { Number } \\
\text { of dogs }\end{array}$ & $\begin{array}{c}\text { Fluid } \\
\text { produced }\end{array}$ & $\begin{array}{c}\text { Range of } \\
\text { values }\end{array}$ \\
\hline & & $\begin{array}{c}\text { ml. per } \text { kgm. } \\
\text { median value } \\
\text { No infusion }\end{array}$ & $\begin{array}{c}5.3 \\
\text { ml. per } \mathrm{kgm} .\end{array}$ \\
Saline infusion* & 38 & 15.0 & 2 to 20 \\
2 to 33
\end{tabular}

* Average amount of fluid administered $=55 \mathrm{ml}$. physiological saline per $\mathrm{kgm}$. body weight.

but that the average output is approximately trebled when the saline transfusion is given. Nearly one-fifth of the administered fluid was recovered by muscle drainage.

Absorption of intracellular constituents. In 4 dogs, 2 treated with drainage, and 2 without, plasma creatine determinations were made ( 7$)$. In Figure 3, it is seen that the plasma creatine, which is essentially normal during the period of

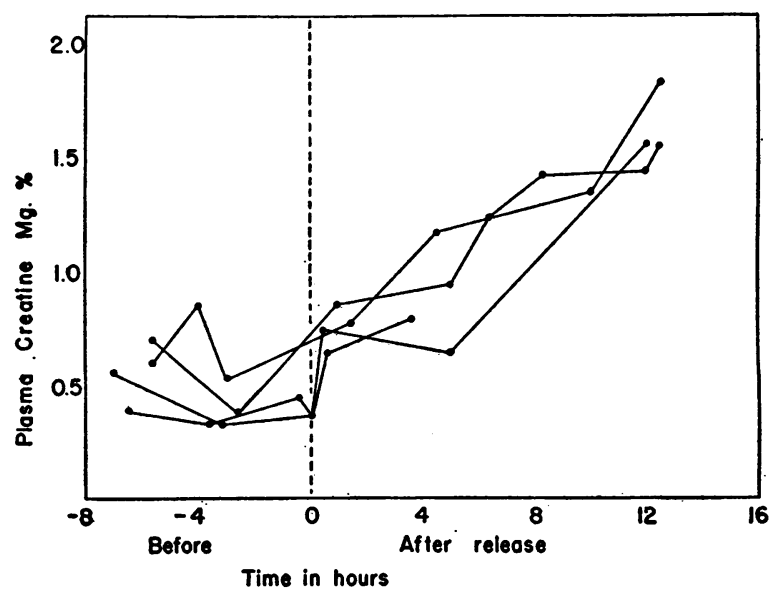

Fig. 3. Graph Illustrating Change in Plasma Creatine Concentration after Release of Muscle Ligatures 
ligation, rises steadily for at least 12 hours after release. This confirms the observation (8) that whole blood creatine rises following muscle trauma. That muscle injured by crushing loses 65 to 70 per cent of its creatine has been shown (9). It is interesting that none of the 4 dogs on which determinations were made developed shock.

The steady increase in plasma creatine in dogs not in shock is especially interesting since it suggests that absorption of a component of muscle occurs in the blood stream. Plasma potassium and phosphate values, on the other hand, have remained essentially constant until shock is present and rise only after renal function has essentially ceased.

Bacterial contamination. Nearly all of the fluids obtained have shown bacterial contamination, at times very heavy, in spite of the aseptic techniques employed. The possible relation of this contamination to the shock produced has been discussed in a preliminary paper (10) and is considered more fully in another paper of this series (11).

\section{DISCUSSION}

The procedure described here was devised to produce a controlled type of traumatic damage (simple ischemia), over a specified time interval, to a definite amount of muscle. Despite the small amount of muscle concerned, shock has occurred in some instances even when other procedures, such as moderate blood losses, were not superimposed. It is noteworthy that local fluid loss and absorption of tissue constituents into the circulation have both been shown to accompany the procedure.

By means of an accurate technique for collecting the fluid which exudes from the anoxic muscle, a separation is possible between those factors present in this fluid and the possible ones absorbed directly into the blood stream, as exemplified by creatine. The absence of shock where extracellular fluid is drained implies that such toxins as may escape directly into the circulation are inadequate in themselves to produce shock when a small muscle mass is involved.

It is surprising how much fluid exudes from these small muscle bundles after anoxia is stopped. It appears obvious that solutes must be reabsorbed into the general circulation when the fluid is allowed continued contact with surrounding tissues. This, of course, would increase the absorption of any toxin which might be present.

There are advantages in not traumatizing an excessive amount of muscle tissue. Certain studies involving differential factors in the production and therapy of traumatic shock may be made when a minimal trauma is used, and yet may be obscured by the overwhelming shock which follows excessive muscular involvement.

Experiments bearing on these questions will be described in the following papers of this series.

\section{SUMMARY}

A method is described for the production of ischemic damage in a reproducible way to a known amount of muscle with subsequent reestablishment of circulation. The amount of tissue involved comprised about 1 per cent of body weight.

This method occasionally produces shock ( 3 out of 10 cases) when uncombined with other procedures detrimental to the circulation.

Both local exudation of fluid and absorption of muscle constituents into the blood stream follow the removal of tourniquets. It is possible, therefore, to assay the relative rôles of these 2 factors in the production of shock by a reproducible traumatic procedure.

Quantitative collection of muscle exudate can be accomplished by this technique.

Intravenous saline transfusions increase the amount of fluid exudation about traumatized tissue.

Advantages of a quantitative method of this type in the critical study of traumatic shock are discussed.

Bibliography follows Paper VI of this series. 